\title{
A percepção dos professores sobre a prática da interdisciplinaridade no ensino de computação para escolares
}

\author{
Euma Silva Santos, William Fabian Machado Vera, Ecivaldo de Souza Matos
}

Departamento de Ciência da Computação - Universidade Federal da Bahia (UFBA) Avenida Ademar de Barros, s/n - CEP 40170-110 - Salvador - BA - Brasil

\{eumasantos, williamfabianmv\} @gmail.com, ecivaldo@ufba.br

\begin{abstract}
This paper presents partial results of a research on perception of interdisciplinarity in computing education by teachers of basic education. For that, a case study was carried out in two public schools with use of Unplugged Computer Science in an interdisciplinary way. The case study was composed of intervention with observation, and teacher's interviews, whose data were analyzed through the method of content analysis. In this analysis It was looking for fundamental categories of interdisciplinarity in teachers' discourses and actions: integration; interaction and reciprocity; and approximation of reality.
\end{abstract}

Resumo. Este artigo tem como objetivo apresentar resultados parciais de uma pesquisa sobre a percepção de interdisciplinaridade nas ações de ensino de computação por professores da educação básica. Para tanto, foi realizado um estudo de caso em duas escolas públicas com uso da Computação Desplugada de modo interdisciplinar. $O$ estudo de caso foi composto de intervenção com observação, e entrevistas com os professores, cujos dados foram analisados por meio do método de análise de conteúdo, com o intuito de identificar categorias fundamentais de interdisciplinaridade nos discursos e ações desses professores: integração; interação e reciprocidade; e aproximação da realidade.

\section{Introdução}

Embora ainda não regulamentado enquanto conteúdo obrigatório nas escolas, o ensino de computação na educação básica (ensinos fundamental e médio) tem importância reconhecida e não é novidade para a comunidade acadêmica de computação. Esse fato fica evidente ao passo que diversas ações têm sido desenvolvidas em vários lugares, dentro e fora do país, com o objetivo de apresentar e apoiar os estudantes no desenvolvimento de competências e habilidades na área de ciência da computação (CC).

Em busca de linguagens mais acessíveis e formas mais lúdicas de realizar ações que envolvam os estudantes da educação básico com os assuntos de computação, muitas vezes são aplicadas ferramentas, técnicas e/ou metodologias para mediar o processo e permitir maior aproximação entre os alunos da educação básica e os assuntos de computação. Uma dessa metodologias é a Computação Desplugada Interdisciplinar (CDI), que propõe ensinar conceitos de computação integrados aos conteúdos curriculares sem utilização de computadores (Paiva, 2015a).

Um fator importante nas atividades do CDI é a independência do uso de hardwares e softwares para aplicação das atividades, facilitando que as intervenções pedagógicas possam ser realizadas em qualquer lugar e ambiente, seja ele escolar ou 
não conforme sua concepção original ${ }^{1}$.

A falta de equipamentos em muitas escolas, principalmente nas unidades da rede pública, inibe que a sua gestão proponha o ensino com uso de computadores. Como a CDI independe desses recursos esse ensino se faz possível. Isso implica também em uma forma coerente de dissociar que o ensino de computação está diretamente ligado a uso de máquinas e outras tecnologias

O Projeto CDI tem também como um dos objetivos estimular o pensamento/raciocínio computacional utilizando-se de atividades onde é possível trabalhar conteúdos de computação em conjunto com outras disciplinas curriculares.

Segundo Paiva (2015b), a Computação Desplugada é uma alternativa para a execução de atividades que estimulem o pensamento/raciocínio computacional. Isso implica dizer que a construção de conhecimento no campo da Computação deve preceder o uso das máquinas, uma vez que a Computação, assim como a Matemática, é uma ciência abstrata e fundamentalmente semiótica, cuja principal função é processar signos.

Outra recurso utilizado no ensino de computação na educação básica com o projeto CDI é a interdisciplinaridade, visto que o CDI se utiliza da relação entre as diversas disciplinas escolares e a computação para, principalmente, facilitar a compreensão de ambas, despertar o raciocínio computacional e estimular novos métodos de aprendizagem.

Fazenda (2008) afirma que "na interdisciplinaridade escolar as noções, finalidades habilidades e técnicas visam favorecer, sobretudo, o processo de aprendizagem respeitando os saberes dos alunos e sua integração" (p. 21). Segundo Ribeiro (2005), a interdisciplinaridade implica em um diálogo entre duas ou mais disciplinas para que haja compartilhamento de conhecimento e enriquecimento de ambos. Dessa forma não é apenas "juntar”, mas compartilhar conhecimentos.

A interdisciplinaridade no ensino e no aprendizado tem contribuído para a construção do saber na sociedade contemporânea e a escola como um lugar de aprendizagem e produção de conhecimento precisa acompanhar e se apropriar dessas ferramentas (Fazenda, 2008).

Partindo desses pressupostos podemos afirmar que o projeto propõe despertar nos alunos uma forma de resolver problemas usando o pensamento/raciocínio computacional por meio de práticas interdisciplinares. Nesse sentido, este artigo tem como objetivo apresentar resultados parciais de uma pesquisa sobre as concepções de interdisciplinaridade nas ações de ensino de computação por professores da educação básica, a partir das ações do CDI em duas escolas públicas de educação básica, com o intuito de identificar categorias fundamentais de interdisciplinaridade nos discursos e ações desses professores.

A interdisciplinaridade só existe se, de fato, ela estiver incorporada nas práticas e nos discursos dos sujeitos escolares. Por isso, antes de avaliarmos a efetividade pedagógica (aprendizado pelos estudantes) dessas ações, faz-se necessário avaliar se de fato alcançamos um dos principais objetivos: a efetiva articulação interdisciplinar na ação docente escolar.

\footnotetext{
${ }^{1}$ Computer Science Unplugged - $\mathrm{http}: / /$ csunplugged.org/
} 


\section{Metodologia}

\subsection{Natureza da pesquisa}

Para esta pesquisa, de natureza qualitativa e interdisciplinar, foram utilizadas abordagens em que o objetivo principal foi entender os sujeitos e seu contexto, por meio de um estudo de caso.

Ao longo do estudo de caso foram utilizadas duas técnicas de registro e tratamento dos dados coletados: diário de bordo e entrevistas. O diário de bordo registrou a observação dos participantes, imagens (fotografias) e relatos das observações durante as intervenções.

\subsection{Caracterização do campo}

O campo de pesquisa consistiu em um conjunto de dois coordenadores pedagógicos e 10 professores do ensino fundamental II e do ensino médio $\left(1^{\circ}\right.$ e $2^{\circ}$ anos $)$ de duas escolas públicas de educação básica em Salvador, conforme Quadro 1.

Quadro 1. Resumo dos professores e coordenadores participantes por série e área de atuação

\begin{tabular}{|l|l|l|}
\hline \multicolumn{1}{|c|}{ Série } & \multicolumn{1}{c|}{ Área } & \multicolumn{1}{c|}{ Função } \\
\hline Ensino Médio & Coordenação Pedagógica & Coordenador 1 \\
\hline Fundamental II & Vice direção & Coordenador 2 \\
\hline $6^{\circ}$ ano - Fundamental II & Matemática & Professor 1 \\
\hline $8^{\circ}$ ano - Fundamental II & Filosofia/Sociologia & Professor 2 \\
\hline $9^{\circ}$ ano - Fundamental II & Filosofia/Sociologia & Professor 3 \\
\hline $8^{\circ}$ ano - Fundamental II & Ciências & Professor 4 \\
\hline $1^{\circ}$ ano - Ensino Médio & Língua Portuguesa & Professor 5 \\
\hline $1^{\circ}$ ano - Fundamental II & Língua Portuguesa & Professor 6 \\
\hline $7^{\circ}$ ano - Fundamental II & Filosofia/Sociologia & Professor 7 \\
\hline $1^{\circ}$ ano - Ensino Médio & Biologia & Professor 8 \\
\hline $1^{\circ}$ ano - Ensino Médio & História & Professor 9 \\
\hline $1^{\circ}$ ano - Ensino Médio & Língua Inglesa & Professor 10 \\
\hline
\end{tabular}

\subsection{Caracterização das intervenções}

No primeiro contato do grupo de pesquisa com os professores, convidamos os interessados a participar do projeto. Desses professores, coletamos algumas informações de contato, sobre suas disciplinas, turmas e respectivos conteúdos. Com essas informações em mãos, o grupo se reuniu para planejamento das atividades. Cada plano de aula foi criado a partir de ideias do grupo com objetivo de ensinar o conteúdo programático de cada professor junto à um conteúdo pedagógico de Computação. Ao longo do processo os professores acompanharam e opinaram acerca da atividade.

Finalizado o processo de elaboração dos planos de aula, as intervenções foram marcadas e aplicadas em datas e horários de aula combinadas com o próprio professor, conforme Quadro 2. 
Quadro 2. Resumo das intervenções realizadas nas escolas

\begin{tabular}{|c|c|c|c|c|}
\hline Resumo da Atividade & Série & $\begin{array}{l}\text { Conteúdo de } \\
\text { Computação }\end{array}$ & $\begin{array}{c}\text { Conteúdo da } \\
\text { Disciplina }\end{array}$ & $\begin{array}{l}\text { Disciplina } \\
\text { Curricular }\end{array}$ \\
\hline $\begin{array}{l}\text { Intervenção 1: Apresentamos o caminho que um } \\
\text { processo percorre na máquina e depois fizemos uma } \\
\text { comparação do processo similar que ocorre no } \\
\text { nosso sistema nervoso. }\end{array}$ & $8^{\circ}$ ano & $\begin{array}{c}\text { Sistemas } \\
\text { Operacionais }\end{array}$ & Sistema Nervoso & Ciências \\
\hline $\begin{array}{l}\text { Intervenção 2: Conversamos e refletimos sobre } \\
\text { como a Indústria Cultural intervém na publicidade e } \\
\text { de como a representação das imagens é feita por } \\
\text { meio do computador. }\end{array}$ & $9^{\circ}$ ano & $\begin{array}{c}\text { Representação } \\
\text { de imagens }\end{array}$ & Indústria & Filosofia \\
\hline $\begin{array}{l}\text { Intervenção 3: Conversamos e refletimos a } \\
\text { respeito das ações das pessoas nas redes sociais e os } \\
\text { reflexos delas nas relações sociais do mundo real. }\end{array}$ & $\begin{array}{c}7^{\circ} \text { e } 8^{\circ} \\
\text { anos }\end{array}$ & Redes Sociais & $\begin{array}{c}\text { Sentido da Vida } \\
\text { e Morte }\end{array}$ & Filosofia \\
\hline $\begin{array}{l}\text { Intervenção 4: Demonstração da construção de um } \\
\text { algoritmo para solução do desafio proposto que } \\
\text { consistia no nivelamento da água em três } \\
\text { recipientes de quantidade distintas. }\end{array}$ & $6^{\circ}$ ano & $\begin{array}{c}\text { Lógica de } \\
\text { Programação }\end{array}$ & $\begin{array}{l}\text { Frações } \\
\text { Decimais }\end{array}$ & Matemática \\
\hline $\begin{array}{l}\text { Intervenção 5: Utilizando o recursos da lógica de } \\
\text { raciocínio através do uso de } \\
\text { condicionais fizemos com que os adores } \\
\text { associassem mais facilmente as regras para } \\
\text { concordância dos verbos ao seu sujeito. }\end{array}$ & $9^{\circ}$ ano & $\begin{array}{c}\text { Operadores } \\
\text { Condicionais }\end{array}$ & $\begin{array}{l}\text { Concordância } \\
\text { Verbal }\end{array}$ & $\begin{array}{c}\text { Língua } \\
\text { Portuguesa }\end{array}$ \\
\hline $\begin{array}{l}\text { Intervenção 6: Explora a analogia entre } \\
\text { Humanismo ter o homem como centro e a IHC } \\
\text { também, perpassando pela semiótica dos símbolos } \\
\text { que estão presentes nas redes. }\end{array}$ & $1^{\circ}$ ano & $\begin{array}{c}\text { IHC } \\
\text { (Usabilidade e } \\
\text { Semiótica) }\end{array}$ & $\begin{array}{l}\text { Características } \\
\text { do Humanismo }\end{array}$ & $\begin{array}{c}\text { Língua } \\
\text { Portuguesa }\end{array}$ \\
\hline $\begin{array}{l}\text { Intervenção 7: Por meio da construção de um } \\
\text { programa são praticadas e fixadas as regras de } \\
\text { formação de plurais regulares no inglês. }\end{array}$ & $1^{\circ}$ ano & $\begin{array}{c}\text { Lógica de } \\
\text { Programação }\end{array}$ & $\begin{array}{l}\text { Regras de } \\
\text { formação do } \\
\text { plural }\end{array}$ & Inglês \\
\hline $\begin{array}{l}\text { Intervenção 8: Utilizando um esboço procuramos } \\
\text { trabalhar o conceito de redes e mostrar a relação/ } \\
\text { ligação entre as informações. }\end{array}$ & $1^{\circ}$ ano & \begin{tabular}{|} 
Topologia de \\
Redes de \\
Computadores
\end{tabular} & $\begin{array}{l}\text { Humanismo, } \\
\text { Classicismo e } \\
\text { Quinhentismo }\end{array}$ & $\begin{array}{c}\text { Língua } \\
\text { Portuguesa }\end{array}$ \\
\hline $\begin{array}{l}\text { Intervenção 9: Explora a relação da importância } \\
\text { das partes da célula para o funcionamento dela e os } \\
\text { componentes de hardware para o funcionamento do } \\
\text { computador. }\end{array}$ & $\begin{array}{c}1^{\circ} \text { e } 2^{\circ} \\
\text { anos }\end{array}$ & $\begin{array}{l}\text { Componentes } \\
\text { básicos de } \\
\text { Hardware }\end{array}$ & $\begin{array}{c}\text { Estrutura e } \\
\text { componentes da } \\
\text { célula }\end{array}$ & Biologia \\
\hline $\begin{array}{l}\text { Intervenção 10: Trazendo elementos da história do } \\
\text { Brasil e capitanias hereditárias é feita uma relação } \\
\text { entre a divisão dessas capitanias e a divisão na } \\
\text { memória do computador. }\end{array}$ & $1^{\circ}$ ano & $\begin{array}{c}\text { Partições de } \\
\text { uma máquina }\end{array}$ & $\begin{array}{l}\text { Capitanias } \\
\text { Hereditárias }\end{array}$ & História \\
\hline
\end{tabular}

\subsection{Procedimentos de coleta e registro dos dados}

A nossa pesquisa tomou como instrumento de observação os diários de bordo. As coletas foram realizadas em sala durante as aplicações de atividades, considerando o comportamento de todos os sujeitos envolvidos: pesquisadores, professor e alunos.

O diário é um instrumento considerado por muitos pesquisadores como uma escrita reflexiva. Segundo Alves (2001): 
o diário pode ser considerado como um registro de experiências pessoais e observações passadas, em que o sujeito que escreve inclui interpretações, opiniões, sentimentos e pensamentos, sob uma forma espontânea de escrita, com a intenção usual de falar de si mesmo. (p.224)

Segundo Stake (1995), as observações dirigem o pesquisador para a compreensão do caso, para isso se faz necessário um registro apurado dos acontecimentos de forma que venham fornecer uma descrição fiel dos fatos e consequentemente venham contribuir com a análise dos dados e relatórios finais.

Durante a aplicação das intervenções, dois ou mais pesquisadores trabalharam dentro da sala de aula exclusivamente na observação e registro dos sujeitos. Posteriormente essas informações foram descritas sob o ponto de vista de cada observador e compartilhadas com o grupo. Além dos diários de bordo, os registros incluem também imagens e/ou filmagens.

Além do diário de bordo foram realizadas entrevistas com os 12 sujeitos (coordenadores pedagógicos e professores) com o objetivo de coletar discursos contidos na fala dos sujeitos. As entrevistas foram individuais ao final das intervenções com os professores participantes das intervenções e com as respectivas coordenações pedagógicas.

O roteiro da entrevista foi elaborado com 15 perguntas abertas com o objetivo de conhecer o professor participante da ação e como é sua relação com os alunos dentro da sala de aula; bem como compreender o entendimento de interdisciplinaridade desse professor diante das ações de CDI desenvolvidas.

As entrevistas foram agendadas conforme disponibilidade de dia e horário de cada professor e coordenação pedagógica e realizadas após aplicação de todas as intervenções no próprio ambiente escolar. Foram realizadas gravações das falas dos professores, mediante termo de consentimento assinado, em seguida as entrevistas foram transcritas e analisadas pelos pesquisadores.

\subsection{Análise de dados}

No processo de tratamento dos dados foi utilizado o método de Análise de Conteúdo. Para Bardin (2009), a Análise de Conteúdo configura-se como um conjunto de técnicas de análise das comunicações que utiliza procedimentos sistemáticos e objetivos de descrição do conteúdo das mensagens. Trata-se de um processo investigativo onde os resultados são resultantes de testes de associação de palavras - estereótipos e conotações. Isso exige que o investigador tenha um esforço duplo que consiste em entender o sentido da comunicação, atuando como um receptor normal, e buscando outra significação ou mensagens implícitas.

A metodologia da análise de conteúdo organiza-se nas seguintes etapas: (i) préanálise; (ii) exploração do material; e (iii) tratamento dos resultados: inferências e interpretação. Durante o processo de organização foram seguidos os seguintes passos:

- definição de questões e problemas;

- levantamento da hipótese ("existe interdisciplinaridade nas intervenções realizadas nas escolas nos ensinos dos fundamentos de computação?”);

- codificação de dados; 
- definição das categorias;

- inferências e interpretações.

Visando favorecer o processo de planejamento de análise, bem como as etapas seguintes, facilitando a visualização dos dados para produção das inferências, utilizouse o software QDA Miner ${ }^{\circledR}$.

\title{
3. Resultados
}

Baseado nos conceitos apontados por Yared (2008) acerca da interdisciplinaridade, inicialmente utilizaríamos as seguintes categorias: integração, movimento, relação dialógica (reciprocidade e troca), protagonismo do sujeito, e aproximação da realidade. Esses termos, segundo a autora estão atrelados à interdisciplinaridade tornando o sujeito um protagonista de sua própria história e evitando que a disciplinaridade se torne vazia.

Segundo Oliveira e Neto (2016), os Parâmetros Curriculares Nacionais (PCN) ressaltam a necessidade de o ensino estar voltado à articulação entre áreas, tanto conceitualmente quanto na prática, para que dessa forma os alunos estejam aptos a relacionar o que estão aprendendo com a sua realidade. Segundo Japiassu (1976), essa articulação entre áreas estabelece a interdisciplinaridade, uma vez que a colaboração entre uma ou mais disciplinas promovem interação e reciprocidade capaz de enriquecer ambas.

Diante desses pressupostos priorizou-se trabalhar na análise das entrevistas com as seguintes categorias: integração; interação e reciprocidade; e aproximação da realidade. Porém ainda que identificadas separadamente, a análise foi realizada a partir da integração dessas categorias, uma vez todas sustentam a interdisciplinaridade como afirma Alves (2008):

\begin{abstract}
$\mathrm{Na}$ realidade, esta visão de interdisciplinaridade estava em seu estágio inicial, de meados dos anos 1970, no qual a integração dos conteúdos era considerada interdisciplinaridade. Porém este é o primeiro passo para a interação entre as pessoas, condição básica para a efetivação de um trabalho interdisciplinar "que só pode ocorrer num regime de coparticipação, reciprocidade, mutualidade". (p. 99)
\end{abstract}

Como resultado dessa análise foram sumarizadas as principais evidências as partir das falas dos professores para cada categoria, conforme Quadro 3. A identificação dos professores e coordenadores entrevistados segue uma ordem crescente seguida da sigla da disciplina que lecionam (LP - Língua Portuguesa, M - Matemática, C Ciências, F/S - Filosofia e/ou Sociologia, H - História, I - Inglês, Q - Química, B Biologia).

Quadro 3. Concepções dos professores acerca das intervenções

\begin{tabular}{|c|c|}
\hline rias & Identificação das categorias nas falas dos professores \\
\hline \multirow{2}{*}{ Integração } & $\begin{array}{l}\text { "....uma forma de facilitar o entendimento dos conteúdos dos alunos em matemática, } \\
\text { [...] e percebi que com aplicação do projeto eles conseguiram ter entendimento melhor } \\
\text { acerca do conteúdo. [...] atenção dos meninos em relação aos conceitos que estavam } \\
\text { sendo abordados naquele momento." (professor } 1 \text { - M) }\end{array}$ \\
\hline & $\begin{array}{l}\text { "...mas eu acho que ele poderia entrar como um conteúdo dentro de uma disciplina } \\
\text { como linguagens, português. Ai poderia ser em Sociologia, poderia ser em alguma } \\
\text { disciplina a aliar o conteúdo." (professor } 2 \text { - F/S) }\end{array}$ \\
\hline
\end{tabular}




\begin{tabular}{|c|c|}
\hline & $\begin{array}{l}\text { "... a organização da metodologia, primeiro de trazer o conceito do tema que nós } \\
\text { estávamos trabalhando, é... passar a parte teórica desse conceito e depois fazer parte } \\
\text { prática que foi a parte da formação daquelas leituras que são chamadas leituras de } \\
\text { máquina depois né?" (professor } 3 \text { - F/S) }\end{array}$ \\
\hline & $\begin{array}{l}\text { "Eu acho que é uma proposta nova, eu acho que tudo que é novo que agrega } \\
\text { construção de conhecimento de uma forma diferenciada, vale a pena." (coordenadora } \\
\text { 1) }\end{array}$ \\
\hline & $\begin{array}{l}\text { “... dando célula pra eles eu digo:ó imagina que nesse momento aqui eu sou o cérebro } \\
\text { e estou numa posição de comando e também vou comparando as paredes, no caso com } \\
\underline{\text { a membrana e eles fizeram isso também direitinho." (professor } \mathbf{8} \text { - B) }} \\
\end{array}$ \\
\hline & $\begin{array}{l}\text { “...eu acho muito importante além das aulas curriculares, também ter outros } \\
\text { instrumentos pra gente trabalhar com a juventude,..” (professor } \mathbf{9}-\boldsymbol{H})\end{array}$ \\
\hline & $\begin{array}{l}\text { "...todos os conteúdos que possam ser agregados são válidos [...] quando colocou que } \\
\text { podia ser para qualquer disciplina, qualquer assunto eu achei muito interessante eu } \\
\text { achei que dá para explorar Muito mais coisa." (professor } 4 \text { - C) }\end{array}$ \\
\hline & $\begin{array}{l}\text { "Como vocês contextualizaram, a contextualização do assunto com a proposta de } \\
\text { atividade." (professor } \mathbf{5}-\mathbf{L P} \text { ) }\end{array}$ \\
\hline & $\begin{array}{l}\text { "...vocês conseguiram unir o assunto, ou seja usou um trabalho interdisciplinar } \\
\text { aliando tanto a computação quanto os dois assuntos trabalhados, ..." (professor } 6 \text { - } \\
\text { LP) }\end{array}$ \\
\hline \multirow{7}{*}{$\begin{array}{l}\text { Interação } e \\
\text { reciprocidade }\end{array}$} & $\begin{array}{l}\text { "...é o fato deles estarem aprendendo a informática de forma interdisciplinar aliada a } \\
\text { uma disciplina, sem perceber que está usando, acontecendo, [...] Quando eles forem } \\
\text { utilizar os computadores, eles perceberão que tudo aquilo ali, eles conseguiram } \\
\text { perceber sem ter tido o, a necessidade de ter tido o acesso a máquina."(coordenador } \\
\text { 2) }\end{array}$ \\
\hline & $\begin{array}{l}\text { "...com aplicação do projeto eles conseguiram ter entendimento melhor acerca do } \\
\text { conteúdo. " [...]Eu particularmente não imaginei que o conteúdo de fração fosse } \\
\text { apresentado da forma com que ele foi, [...] e depois eles perceberam que tudo que é } \\
\text { dito eles fazem no computador }[. . .] \text { após a aplicação desse conteúdo por meio da } \\
\text { computação desplugada eu percebi que eles já estavam com a noção melhor de } \\
\text { fração. } \\
\text { professor } 1 \text { - M) }\end{array}$ \\
\hline & $\begin{array}{l}\text { "Acho que principalmente isso. Acho não, eu tenho certeza. Acho que veio coincidir } \\
\text { com o tema e eu acho que reafirmou tudo que eu já vinha discutindo. "(professor } 2 \text { - } \\
\boldsymbol{F} / \mathbf{S})\end{array}$ \\
\hline & $\begin{array}{l}\text { "... como uma forma de construção do conhecimento, [...] expandindo mais ainda } \\
\text { esse leque de conhecimento, é maravilhoso!"(coordenador 1) }\end{array}$ \\
\hline & $\begin{array}{l}\text { “...eles começaram a entender a proposta e começaram a interligar com o assunto. } \\
\text { [...] conseguiu completamente ser penetrado com outra linguagem. " (professor } 9 \text { - H) }\end{array}$ \\
\hline & $\begin{array}{l}\text { "E eles participando, entendendo, interagindo, isso foi o que mais me chamou } \\
\text { atenção." (professor 10-I) }\end{array}$ \\
\hline & $\begin{array}{l}\text { “...eu entendi que após eles terem trabalhado a atividade interdisciplinar eles fizeram } \\
\text { a tarefa que vocês pediram e eles conseguiram assimilar a minha aula, fizeram a } \\
\text { minha prova, e eles conseguiram assimilar o conteúdo programático sobre } \\
\text { quinhentismo direitinho." (professor } \mathbf{6}-\mathbf{L P} \text { ) }\end{array}$ \\
\hline $\begin{array}{l}\text { Aproximação } \\
\text { da realidade }\end{array}$ & $\begin{array}{l}\text { "...achei interessante, visto que tudo que é diferente e tecnológico, pra, hoje em dia } \\
\text { principalmente pros alunos, torna-se mais atraente ,para eles, no que se refere ao } \\
\text { aprendizado." (coordenador 2) }\end{array}$ \\
\hline
\end{tabular}




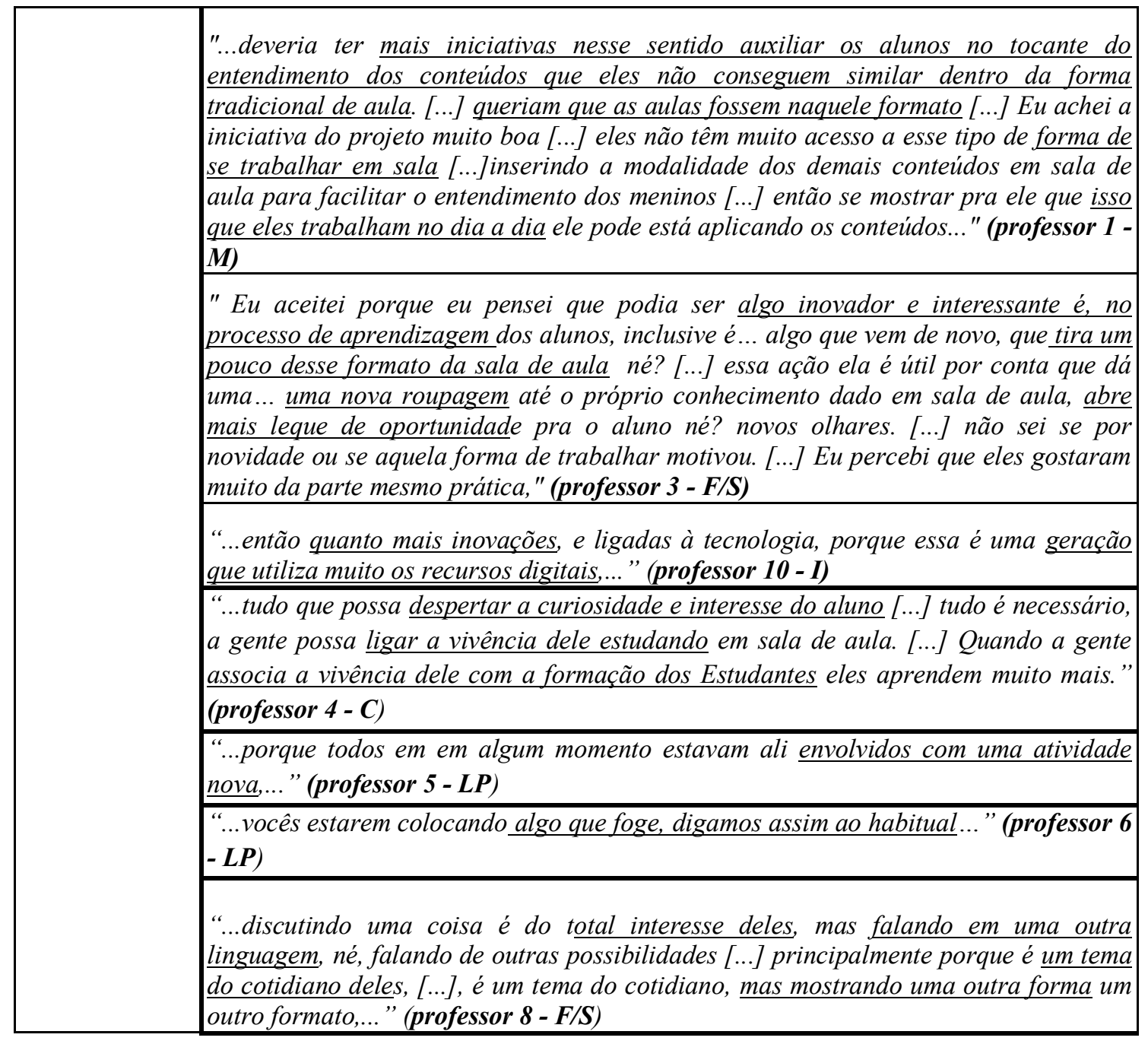

Por meio da interpretações e inferências após a categorização, foi possível identificar pelo menos uma das categorias nas falas de cada professor. A pesquisa evidencia que embora os professores concordassem que projetos interdisciplinares contribuam com o aprendizado, muitos não falam claramente da percepção de interdisciplinaridade nos projetos, sendo necessária uma análise criteriosa dos dados para afirmar o seu entendimento sobre o tema.

Visando analisar as concepções dos professores e coordenadores das escolas acerca da interdisciplinaridade as perguntas foram referentes à importância e expectativa do projeto CDI na escola e os resultados obtidos após a aplicação das atividades.

Foi perceptível que na concepção da maioria dos professores a interdisciplinaridade está relacionada à integração das disciplinas e conteúdos. Isso ratifica mais uma vez o que Japiassu (1976) trata como articulação entre áreas. Para Alves (2008) a integração é o primeiro passo para a interação entre as pessoas, condição básica para a efetivação de um trabalho interdisciplinar.

A segunda categoria mais percebida pelos professores foi a aproximação da realidade. Fazenda (2002) afirma que além do desenvolvimento de novos saberes, a interdisciplinaridade na educação favorece novas formas de aproximação da realidade 
social e novas leituras das dimensões socioculturais das comunidades humanas. Quanto mais a escola contextualiza seus saberes com a realidade do sujeito mais proveitoso é o processo de aprendizagem e o aluno tem interesse com essa aproximação. Quase $70 \%$ dos professores se referiram ao projeto como algo novo, inovador, associado ao cotidiano e a vivência do aluno. Acreditamos, portanto que a interdisciplinaridade se aprende praticando ou vivendo em situação real e contextualizada (Fazenda, 2002).

Para finalizar as buscas por concepções acerca da interdisciplinaridade nas entrevistas destacamos aqui a interação e reciprocidade. A reciprocidade é definida por Fazenda como uma das teorias da interdisciplinaridade e aponta para a possibilidade de abrir fronteiras e criar zonas de interseção com o outro. Essa interseção tratada pela autora é visível nas opiniões dos professores, embora não estejam explícitas como observamos na fala do professor 1 - LP “... é o fato deles estarem aprendendo a informática de forma interdisciplinar aliada a uma disciplina, sem perceber que está usando, acontecendo, ...”. Contudo percebemos que há uma interação entre as disciplinas que mutuamente se completam permitindo que o aluno compreenda o todo.

\section{Considerações finais}

Este artigo apresentou resultados parciais de uma pesquisa sobre a percepção da interdisciplinaridade nas ações de ensino de computação por professores da educação básica. Esta pesquisa foi realizada em duas escolas públicas de Salvador por meio de intervenções do Projeto Computação Desplugada Interdisciplinar. A análise dos diários de bordo e das entrevistas realizadas com os professores voluntários deste projeto permitiu verificar que a maioria dos professores compreende a interdisciplinaridade como a integração de uma ou mais disciplinas para entendimento de assuntos relacionados a ambas. Constatamos também que o professor entende que a prática interdisciplinar na escola contribui no processo de aprendizagem do aluno, contudo os conceitos ainda precisam ser aprimorados.

Todos os entrevistados afirmaram que projetos interdisciplinares motivam o aluno, pois na maioria das vezes esse tipo de metodologia cria situações que aproximam o aluno da sua realidade, fator que facilita o aluno compreender situações complexas.

Partindo dessas concepções iniciais dos professores e coordenadores que participaram do projeto CDI e embasados no conceito de interdisciplinaridade postulado por Fazenda (2008), podemos concluir que existe a necessidade de mais reflexões teóricas e ações efetivamente integradoras na/com/para a escola, tanto por parte dos pesquisadores quanto da comunidade escolar. Essas reflexões e ações permitirão maior compreensão do conceito de interdisciplinaridade e contribuirá futuramente para as novas intervenções do CDI.

\section{Agradecimentos}

Os autores agradecem ao CNPq (Conselho Nacional de Desenvolvimento Científico e Tecnológico) e à FAPESB (Fundação de Amparo à Pesquisa do Estado da Bahia) pelo apoio financeiro a esta pesquisa e aos integrantes do Projeto Computação Desplugada Interdisciplinar da UFBA por atuarem nas intervenções.

\section{Referências}

Alves, F. C. (2001). Diário - um contributo para o desenvolvimento profissional dos professores e estudo dos seus dilemas. Instituto politécnico de Viseu. Disponível em 
$<$ http://www.ipv.pt/millenium/Millenium29/30.pdf $>$ acessado em 12 de fevereiro de 2017.

Alves, A. (2008). "Interdisciplinaridade e matemática". Fazenda, I. (org.) O que é interdisciplinaridade. São Paulo. Cortez. p. 97-111.

André, M. E. D. A. (2005). Estudo de Caso em Pesquisa e avaliação educacional. Brasília: Liber Livro Editora.

Bell, T., Witten, I. H.; Felows, M. (2011). Computer Science Unplugged. Csunplugged.org.

Cañete, L. S. C. (2010). O diário de bordo como instrumento de reflexão crítica da prática do professor. Belo Horizonte, UFMG.

Cassiani, S. B.; Carili, M. H. L.; Pelá, N.T.R. (1999). A teoria fundamentada nos dados como abordagem da pesquisa interpretativa. Rev.latino-am.enfermagem, v. 4, n. 3, p. $75-88$.

Fazenda, I. (2002). Dicionário em construção: Interdisciplinaridade. 2. ed. São Paulo: Cortez.

. (2008). "Interdisciplinaridade-Transdisciplinaridade: visões culturais e epistemológicas". Fazenda, I. (org.) $O$ que é interdisciplinaridade. São Paulo. Cortez. p. 17-28.

Fernandes, E. M.; Maia, A. (2001). Grounded theory: métodos e técnicas de avaliação: contributos para a prática e investigação psicológicas. Braga: Universidade do Minho. Centro de Estudos em Educação e Psicologia. p. 49-76.

Japiassu, H. (1976). Interdisciplinaridade e patologia do saber. Rio de Janeiro: Imago.

Ludke, M.; André, M. E. D. A. (1986). Pesquisa em Educação: abordagens qualitativas. São Paulo: EPU.

Matos, E. S., Paiva, L. F., Miranda, A. M., Ferreira, A. C. C; Barreto, J. S. (2015) Experiência prática interdisciplinar do raciocínio computacional em atividades de computação desplugada na educação básica. In: XXI Workshop de Informática na Escola, Maceió. Anais do Workshop de Informática na Escola. Porto Alegre: Sociedade Brasileira de Computação, 2015. v. 21. p. 256-265.

Paiva, F., Ferreira, A. C., Rocha, C., Barreto, J., Lopes, R. H., Melhor A. M.; Matos, E. S. (2015) Uma Experiência Piloto de Integração Curricular do Raciocínio Computacional na Educação Básica. I Workshop de Ensino em Pensamento Computacional, Algoritmos e Programação. In: Anais dos Workshops do Congresso Brasileiro de Informática na Educação. Porto Alegre: SBC, v. 4. p. 1300-1309.

Ribeiro, J. S. (2005). Informática na Educação: teoria \& prática. Interdisciplinaridade, Porto Alegre, v. 8, n. 2.

Stake, E.E. (1978). The Case Study Method in Social Inquiry. Educational Researcher, v. 7, n. 2.

Yared, I. (1995). Interdisciplinaridade e sistema preventivo: sonho-realidade. Lorena: Quadrante. 